\title{
ANALISIS SISTEM INFORMASI AKUNTANSI PENGGAJIAN DAN PENGUPAHAN DALAM UPAYA PENGENDALIAN INTERNAL PADA PT. GEMILANG EMAS INDONESIA
}

\author{
Brenda Langi ${ }^{1}$, David P. E. Saerang ${ }^{2}$, Natalia Y. T. Gerungai ${ }^{3}$ \\ 1,2,3 Jurusan Akuntansi, Fakultas Ekonomi dan Bisnis Universitas Sam Ratulangi, Jl. Kampus Bahu, Manado, \\ 95115, Indonesia \\ E-mail : brendalangi12@gmail.com
}

\begin{abstract}
Payroll and wages accounting information system are important in the enterprise systems that help in decision making and implementation of the payroll and wage employees. Internal control system is a system that protects wealth and enterprise accounting data. This study aims to determine how the payroll accounting information system and wage PT. Gemilang Emas Indonesia and whether the system supports the company's internal control efforts. Methods analysis used in this research is descriptive analysis. The results showed payroll accounting information system and wages in PT. Gemilang Emas Indonesia does not yet support the internal control efforts. Still a lack of segregation of duties in the organizational structure and practices of healthy companies.
\end{abstract}

Keywords: Accounting Information Systems, Payroll, Wages, Internal Control

\section{PENDAHULUAN}

Perkembangan perekonomian semakin berkembang dari waktu ke waktu. Setiap perusahaan yang ada pasti mempunyai maksud dan tujuan yang krang lebih sama yaitu memperoleh laba yang besar. Dalam mendukung maksud dan tujuan tersebut perusahaan membutuhkan adanya sumber daya, dari sumber daya yang ada, salah satu sumber daya yang penting ialah sumber daya manusia atau karyawan. Karyawan yang berkualitas akan melakukan pertimbagan untuk kesejahteraan diri sendiri dan keluarga. Pembayaran jasa karyawan atas apa yang telah mereka berikan untuk perusahaan dibedakan menjadi dua jenis, yaitu gaji dan upah. Gaji dan upah ialah unsur penting dan sensitif di dalam perusahaan. Oleh sebab itu, dalam pengelolahan gaji dan upah perusahaan membutuhkan penanganan yang tepat, teratur, dan efektif oleh semua bagian yang terkait. Agar penanganan yang dilakukan oleh setiap bagian yang terkait berjalan lancar maka perusahaan membutuhkan sistem informasi akuntansi penggajian dan pengupahan.

PT. Gemilang Emas Indonesia merupakan sebuah perusahaan yang bergerak pada bidang perdangangan telekomunikasi. Proses perhitungan dan pembayaran gaji dikelola langsung oleh perusahaan dan dibayarkan secara rutin setiap bulannya. Pada PT. Gemilang Emas Indonesia Manado, terdapat masalah yang terjadi pada sistem pembayaran gaji. Pada saat perusahaan melakukan pembayaran gaji, karyawan tidak melakukan tanda tangan yang merupakan bukti penerimaan gaji. Terdapat juga masalah lain di mana bagian pencatatan waktu hadir juga melakukan pembuatan daftar gaji. Hal ini dikhawatirkan dapat menimbulkan tindak kecurangan. Masalah lain juga terdapat pada proses absensi di mana tidak adanya pengawasan khusus dari bagian yang terkait. Masalah ini dikhawatirkan akan mengakibatkan karyawan datang terlambat dan pulang tidak sesuai dengan waktu pulang kerja. Perusahaan dapat melakukan pencegahan penyelewengan dengan memanfaatkan sistem pengendalian internal. Penerapan dan pelaksanaan pengendalian internal menjadi hal yang penting dalam menentukan potensi kesalahan dan ketidakberesan serta dampak yang akan terjadi pada laporan keuangan (Tontoli, 2017 : 231). 


\section{TINJAUAN PUSTAKA}

Pengertian Sistem. Sistem ialah sekumpulan unsur yang saling berhubungan satu dengan yang lain dan memiliki fungsi yang sama dalam mencapai tujuan (Mulyadi, $2016: 2$ ). Sistem ialah gabungan dari sub bagian atau bagian apapun baik dalam bentuk fisik maupun bentuk non fisik yang saling berhubungan satu sama lain dan bekerja bersama secara harmonis dalam mencapai suatu tujuan tertentu (Susanto, $2013: 22$ ).

Pengertian Sistem Akuntansi. Sistem akuntansi merupakan gabungan dari elemen formulir, jurnal, buku besar, buku pembantu, dan laporan keuangan yang akan dimanfaatkan oleh manajemen dalam mencapai tujuan perusahaan (Sujarweni, $2015: 3$ ).

Sistem Informasi Akuntansi Penggajian dan Pengupahan. Gaji ialah pembayaran atas pemberian jasa yang telah dilakukan dam diberikan oleh karyawan yang memiliki jenjang jabatan manajer, sedangkan upah ialah pembayaran atas pemberian jasa yang telah dilaksanakan oleh karyawan pelaksana. Sistem akuntansi penggajian dan pengupahan ialah sistem yang dipakai oleh perusahaan untuk memberikan upah dan gaji kepada para karyawan atas pemberian jasa yang mereka berikan (Sujarweni, $2015: 127$ ).

Fungsi-fungsi yang Terkait. Menurut Mulyadi (2016 : 382) fungsi-fungsi yang terkait di dalam sistem akuntansi penggajian yaitu: (1) Fungsi Kepegawaian; (2) Fungsi Pencatatan Waktu Hadir; (3) Fungsi Pembuat Daftar Gaji; (4) Fungsi Akuntansi; dan (5) Fungsi Keuangan.

Dokumen-dokumen yang Digunakan. Menurut Mulyadi (2016 : 310), dokumen-dokumen yang digunakan di dalam sistem akuntansi gaji dan upah adalah: (1) Dokumen pendukung perubahan gaji; (2) Kartu jam hadir; (3) Kartu jam kerja; (4) Daftar gaji; (5) Rekap daftar gaji; (6) Surat pernyataan gaji; (7) Amplop gaji; dan (8) Bukti kas keluar.

Catatan-catatan Akuntansi yang Digunakan. Mulyadi (2016 : 317) menyatakan catatan-catatan akuntansi yang digunakan di dalam pencatatan gaji dan upah meliputi: (1) Jurnal Umum; (2) Kartu harga pokok produk; (3) Kartu biaya; dan (4) Kartu penghasilan karyawan.

Jaringan Prosedur Pecatatan Sistem Akuntansi Penggajian. Mulyadi (2016 : 320) menyatakan bahwa jaringan prosedur pencatatan sistem akuntansi penggajian meliputi: (1) Prosedur pencatatan waktu hadir; (2) Prosedur pembuatan daftar gaji; (3) Prosedur pembuatan bukti kas keluar; dan (4) Prosedur pembayaran gaji.

Sistem Pengendalian Internal. Pengendalian internal ialah elemen dari sistem yang mencakup struktur organisasi, cara, dan ukuran yang dipadukan guna menjaga kekayaan organisasi, memeriksa keandalan dan ketelitian dari data akuntansi, mendorong kemampuan dan mendorong peraturan manajemen dipatuhi (Mulyadi, $2013: 6$ ).

\section{METODE PENELITIAN}

Jenis Penelitian. Penelitian ini menggunakan jenis penelitian deskritif dengan menggumpulkan data-data penelitian yang diperoleh dari PT. Gemilang Emas Indonesia Manado mengenai permasalahan penelitian.

Tempat dan Waktu Penelitian. Lokasi pada penelitian ini bertempat di PT. Gemilang Emas Indonesia Jalan Pierre Tendean, Boulevard kompleks Ruko Megastyle Blok IA No. 39-40 Kawasan Megamas Manado. Waktu pelaksanaan penelitian dimulai pada bulan Juli sampai Oktober 2018.

\section{Jenis, Sumber dan Metode Pengumpulan data}

Jenis data. Jenis data di dalam penelitian ini ialah data kualitatif. Peneliti mengambil data kualitatif dari PT. Gemilang Emas Indonesia Manado berupa data non-numerik seperti hasil wawancara mengenai sistem informasi akuntansi penggajian dan pengupahan serta sistem pengendalian internal yang dijalankan perusahaan. 
Sumber data. Dalam penelitian ini, peneliti melakukan pengumpulan data dengan menggunakan sumber data primer. Data primer dalam penelitian ini adalah data-data dalam proses sistem akuntansi penggajian dan pengupahan serta sistem pengendalian internal yang gunakan perusahaan.

Metode Pengumpulan data. Peneliti melakukan wawancara terhadap pimpinan perusahaan, manajer keuangan, manajer personalia, manajer akuntansi dan staf yang terkait dengan pengelolaan gaji dan upah pada PT. Gemilang Emas Indonesia Manado untuk mengetahui sistem akuntansi penggajian dan pengupahan serta pengendalian internal yang dilakukan perusahaan.

Metode Analisis. Metode analisis data pada penelitian ini adalah analisis deskriptif. Analisis deskriptif yaitu menganalisa dan mendekripsikan serta membandingkan data yang diperoleh dari PT. Gemilang Emas Indonesia dengan teori yang dipakai sehingga dapat memberikan informasi dan dapat ditarik kesimpulan.

\section{HASIL PENELITIAN DAN PEMBAHASAN}

\subsection{Hasil Penelitian}

\section{Fungsi-fungsi yang Terkait}

1. Fungsi personalia. Pada PT. Gemilang Emas Indonesia fungsi personalia dijalankan oleh bagian HRD (Human Resources Development). Bagian HRD bertanggung jawab dalam mencari atau merekrut karyawan baru melalui media massa, melakukan seleksi dan wawancara, mengatur penempatan dan mutasi karyawan, menentukan gaji karyawan, serta pemberhentian karyawan. Dalam menjalankan fungsi personalia, $H R D$ juga bertanggung jawab atas pencatatan waktu hadir karyawan dengan menggunakan mesin finger print dan melakukan rekapitulasi kehadiran karyawan setiap bulan dengan melakukan print out finger print serta membuat daftar gaji karyawan yang akan dibayarkan setiap bulannya dan diberikan pada bagian akuntansi dan keuangan untuk pencatatan dan pembayaran gaji.

2. Fungsi akuntansi. Fungsi ini dijalankan oleh bagian akuntansi. Pada PT. Gemilang Emas Indonesia bagian akuntansi bertanggung jawab dalam melakukan pencatatan yang berhubungan dengan pembayaran gaji seperti utang gaji dan utang pajak. Bagian ini juga bertanggung jawab dalam melakukan pemeriksaan ulang daftar gaji yang dibuat oleh bagian $H R D$ dan mengeluarkan perintah pengeluaran uang dan diteruskan pada bagian keuangan untuk pembayaran gaji dan melakukan pencatatan uang keluar.

3. Fungsi Keuangan. Pada PT. Gemilang Emas Indonesia bagian keuangan menjalankan fungsi keuangan. Bagian ini memiliki tanggung jawab dalam membayar gaji karyawan. Bagian keuangan melakukan pembayaran gaji melalui bank dengan cara melalukan transfer uang langsung ke rekening-rekening karyawan. Bagian keuangan selanjutnya memberikan bukti transfer ke bagian akuntansi untuk melakukan pencatatan uang keluar melalui sistem pencatatan yang dipakai perusahaan yaitu software accurate accounting.

Dokumen-dokumen yang Digunakan. Dokumen-dokumen yang digunakan di dalam sistem informasi akuntansi penggajian dan pengupahan pada PT. Gemilang Emas Indonesia Manado, yaitu: (1) Surat pendukung perubahan gaji; (2) Kartu jam hadir; (3) Daftar gaji karyawan; (4) Surat Perintah Pembayaran Gaji; dan (5) Bukti Transfer.

Catatan-catatan Akuntansi yang Digunakan. Jurnal umum dan Buku besar.

Jaringan Prosedur Pencatatan Sistem Penggajian

1. Prosedur pencatatan waktu hadir. Prosedur ini bertujuan untuk mencatat waktu hadir karyawan. Pencatatan waktu hadir karyawan pada PT. Gemilang Emas Indonesia menggunakan finger print, dimana karyawan melakukan scan sidik jari sebelum jam masuk kantor dan melakukan scan sidik jari kembali pada jam pulang kantor. Setiap 
bulan bagian HRD akan melakukan print out finger print. Data print out finger print akan menjadi salah satu acuan dalam menentukan gaji karyawan.

2. Prosedur pembuatan daftar gaji dan upah. Dalam prosedur pembuatan daftar gaji, bagian $H R D$ membuat daftar gaji karyawan setiap bulan. Pada PT. Gemilang Emas Indonesia daftar gaji karyawan berisi gaji pokok dan insentif serta potongan-potongan berupa PPh 21 dan BPJS Ketenagakerjaan dan cacat lain karyawan.

3. Prosedur pembayaran gaji dan upah. Dalam prosedur ini, bagian akuntansi menerima daftar gaji dari bagian $H R D$ dan melakukan perhitungan gaji. Bagian akuntansi kemudian membuat surat perintah pengeluaran uang yang akan diteruskan pada bagian keuangan. Bagian keuangan kemudian melakukan pembayaran gaji karyawan melalui bank. Pihak bank melakukan transfer gaji ke rekening masing-masing karyawan sesuai dengan jumlah masing-masing gaji yang terdapat pada daftar yang berisi jumlah gaji, nama karyawan dan nomor rekening karyawan yang bersangkutan. Setelah itu, bagian akuntansi menyerahkan bukti transfer ke bagian akuntansi. Bagian akuntansi nantinya akan mengisi transaksi tersebut ke software accurate accounting dan secara otomatis akan tercatat ke jurnal umum dan buku besar pada sistem.

Unsur-Unsur Pengendalian Internal PT. Gemilang Emas Indonesia. Unsur-unsur pengendalian internal dalam sistem informasi akuntansi penggajian dan pengupahan pada PT. Gemilang Emas Indonesia Manado, yaitu:

a. Organisasi

1. Fungsi pembuat daftar gaji terpisah dengan fungsi keuangan.

2. Fungsi pencatatan waktu hadir tidak terpisah dengan pembuat daftar gaji.

b. Sistem otorisasi dan Prosedur pencatatan

1. Setiap nama yang tercantum dalam daftar gaji karyawan memiliki surat keputusan pengangakatan sebagai karyawan PT. Gemilang Emas Indonesia yang ditandatangani oleh Direktur Utama.

2. Setiap adanya perubahan dan potongan gaji karyawan selain PPh 21 dan BPJS Ketenagakerjaan didasarkan pada surat keputusan diotorisasi oleh bagian $H R D$.

3. Data print out fingerprint dan daftar gaji diotorisasi oleh bagian $H R D$.

4. Perintah pengeluaran uang diperiksa dan disetujui oleh bagian akuntansi.

5. Perubahan catatan penghasilan karyawan direkonsiliasi dengan daftar gaji karyawan.

c. Praktik yang sehat

1. Pemasukan jam hadir dengan menggunakan sidik jari pada mesin fingerprint tidak diawasi oleh bagian $H R D$.

2. Pembuatan daftar gaji diperiksa dan diotorisasi oleh bagian akuntansi sebelum bagian keuangan melakukan pembayaran.

3. Perhitungan $\mathrm{PPh} 21$ direkonsiliasi dengan catatan penghasilan karyawan

4. Catatan penghasilan karyawan disimpan oleh bagian $H R D$.

\subsection{Pembahasan}

Fungsi yang Terkait. Berdasarkan penelitian yang dilakukan fungsi-fungsi yang terkait dalam sistem akuntansi penggajian pada PT. Gemilang Emas Indonesia adalah fungsi personalia, fungsi akuntansi, dan fungsi keuangan. Fungsi-fungsi yang terkait dengan sistem penggajian pada PT. Gemilang Emas Indonesia belum sesuai dengan teori yang ada dan belum cukup baik dalam upaya mendukung pengendalian internal. Hal ini dapat dilihat dari tidak adanya fungsi pencatat waktu hadir karyawan dan fungsi pembuat daftar gaji karyawan.

Dokumen-dokumen yang Digunakan. Berdasarkan penelitian yang dilakukan dokumen-dokumen yang dipakai di dalam sistem akuntansi penggajian perusahaan sudah cukup baik namun belum sepenuhnya sesuai dengan teori yang ada. Pada PT. Gemilang 
Emas Indonesia amplop gaji tidak lagi digunakan karena pembayaran gaji dilakukan dengan cara mentranfer uang gaji langsung ke rekening karyawan melalui bank.

Catatan-catatan Akuntansi yang Digunakan. Berdasarkan penelitian yang dilakukan catatan-catatan akuntansi yang digunakan PT. Gemilang Emas Indonesia sudah baik. Perusahaan melakukan pemasukan data transaksi yang berhubungan dengan proses penggajian ke dalam software kemudian dibuat jurnal umum dan buku besar pada software yang sama.

Jaringan Prosedur Pencatatan Sistem Penggajian. Berdasarkan penelitian yang dilakukan jaringan prosedur dalam sistem akuntansi penggajian pada PT. Gemilang Emas Indonesia yaitu prosedur pencatatan waktu hadir, prosedur pembuatan daftar gaji, prosedur distribusi biaya gaji, prosedur pembuatan bukti kas keluar, dan prosedur pembayaran gaji. Jaringan prosedur dalam sistem akuntansi penggajian pada PT. Gemilang Emas Indonesia sudah berjalan dengan baik dan sesuai dengan teori yang ada.

\section{KESIMPULAN DAN SARAN}

\subsection{Kesimpulan}

Berdasarkan hasil penelitian dan pembahasan, maka peneliti menarik kesimpulan bahwa sistem akuntansi penggajian PT. Gemilang Emas Indonesia belum sepenunhnya mendukung dalam upaya pengendalian internal. Hal ini dapat dilihat dari masih adanya kekurangan dalam pemisahan dan pembagian tugas dalam struktur organisasi dan praktik yang sehat.

\subsection{Saran}

Berdasarkan analisa data yang telah dibahas sebelumnya, maka penulis memberikan saran antara lain:

1. Dalam menjalankan proses penggajian PT. Gemilang Emas Indonesia sebaiknya memperbaiki struktur organisasi dengan menambah fungsi pencatatan waktu hadir dan fungsi pembuat daftar gaji agar tidak ada perangkapan tugas yang dilakukan bagian $H R D$.

2. PT. Gemilang Emas Indonesia perlu meningkatkan pengawasan terhadap kedisplinan dari karyawan baik dalam hal absensi maupun dalam menjalankan tugas dan fungsi masingmasing bagian.

3. PT. Gemilang Emas Indonesia perlu lebih memperhatikan dan mengikuti perkembangan teknologi yang ada yang berhubungan dengan sistem penggajian perusahaan.

\section{DAFTAR PUSTAKA}

Baridwan, Zaki. 2013. Sistem Informasi Akuntansi. Edisi kedua. YKPN. Yogyakarta.

Susanto, Azhar. 2013. Sistem Informasi Akuntansi. Lingga Jaya. Bandung

Kapoh, Octaviani M., Ilat, Ventje., dan Warongan, Jessy D. L. 2017. Analisis Pelaksanaan Sistem Pengendalian Internal Pada Inspektorat Kabupaten Minahasa Utara. https://ejournal.unsrat.ac.id/index.php/gc/article/view/17484/17019. Jurnal Riset Akuntansi Going Concern 12(2): 213-223.

Marau, Maria Marisa., Nangoi, Grace B., dan Manossoh, Hendrik. 2016. Evaluasi Pengendalian Intern Pada Siklus Penggajian PT. Anekaloka Indotuna Di Bitung. https://ejournal.unsrat.ac.id/index.php/gc/article/view/13130/127 15. Jurnal Riset Akuntansi Going Concern 11(3): 51-56.

Mulyadi. 2016. Sistem Akuntansi. Edisi Ketiga. Salemba Empat. Jakarta.

Pratama, I Putu Agus Eka. 2014. Sistem Informasi dan Implementansinya. Informatika. Bandung. 
Rompas, Richard Antonio., Pangemanan, Sifrid., dan Kalalo, Meily. 2018. Evaluasi Efektivitas Pengendalian Intern Sistem Informasi Akuntansi Penggajian RSUP. Prof. Dr. $\quad R$. $\quad D . \quad$ Kandou Manado. https://ejournal.unsrat.ac.id/index.php/gc/article/view/19123/1868. Jurnal Riset Akuntansi Going Concern 13(2): 220-232.

Roring, Pricilla Roxenne. Karamoy, Herman. Pangemanan, Sifrid. 2018. Evaluasi Penerapan Sistem Akuntansi Pengeluaran Kas Penggajian Pegawai Negeri Sipil Di Badan Kepegawaian Daerah Provinsi Sulawesi Utara. https://ejournal.unsrat.ac.id/index.php/gc/article/view/19070/18631. Jurnal Riset Akuntansi Going Concern 13(2): 21-29.

Sugiyono. 2015. Metode Penelitian Kuantitatif, Kualitatif, dan R\&D. Alfabeta. Bandung.

Sujarweni, V. Wiratna. 2015. Sistem Akuntansi. Pustaka Baru Press. Yogyakarta.

Tampi, Ribka. 2015. Analisis Sistem Pengendalian Intern Terhadap Penggajian pada Grand Sentral Supermarket Tomohon. Jurnal EMBA 3(3): 63-73.

Tontoli, Sitti Amanah, Elim, Inggriani., dan Tirayoh, Victorina Z. 2017. Analisis Efektivitas Pengendalian Intern Persediaan Barang Dagangan Pada PT. Kimia Farma Apotek 74 Manado. https://ejournal.unsrat.ac.id/index.php/gc/article/view/17548/17080. Jurnal Riset Akuntansi Going Concern 12(2): 231-240. 